\title{
EFFECT OF ANCHORAGE DEPENDENCY ON GROWTH RATE AND MONOCLONAL ANTIBODY PRODUCTION OF HYBRIDOMA CELLS
}

\author{
Gyun Min Lee ${ }^{1 *}$, Thomas K. Huard ${ }^{2}$ and Bernhard O. Palsson ${ }^{1}$ \\ ${ }^{1}$ Department of Chemical Engineering and \\ ${ }^{2}$ Department of Internal Medicine \\ University of Michigan \\ Ann Arbor, MI 48109
}

\begin{abstract}
Hybridoma cells (S3H5/ $/ 2 \mathrm{bA} 2$ ) are found to grow either in suspension or as attached to the surface of cell culture $T$ flask. Cell growth rates and monoclonal antibody (MAB) production rates of both suspended and attached cells were examined. Although the percentage of viable cells was higher for the attached cells, cells growing in suspension showed almost the same charateristics as cells attached to the flasks with respect to cell growth and MAB production rate. Cell attachment increased with increasing serum concentrations up to $5 \%$ and remained essentially constant at cell densities of about $2 \cdot 10^{5} / \mathrm{cm}^{2}$.

No differences in cell growth rate and MAB production could be attributed to anchorage dependent growth.
\end{abstract}

\section{INTRODUCTION}

Monoclonal antibodies (MABs) are currently an important product derived from large-scale mammalian cell culture. MABs are widely used for in vitro diagonostics, protein purifications, tumor imaging and immunotherapy (Kitano et al., 1986). The increasing demand for MABs has motivated recent efforts to develop large scale in vitro production of MABs by hybridoma cells. Hybridoma cells which were first introduced by Köhler and Milstein (1975) are generally known as an anchorage independent cells (AICs). AICs are advantageous for large scale product of cells and cell products. However, when some hybridoma cells grow in $\mathrm{T}$ flasks, significant number of cells attach to the surface of $T$ flasks. Therefore, it is important to determine whether attached cells have the same characteristics as cells in suspension with respect to cell growth and MABs production.

In this study, we have investigated the effect of anchorage dependency on cell growth rate and MAB production of hybridoma cells ( $33 \mathrm{H} 5 / \gamma 2 \mathrm{bA} 2$ ). Furthermore, the effect of serum concentration in culture medium on cell anchorage was investigated.

\section{MATERIALS AND METHODS}

\section{Cell line, medium and culture maintenance}

The murine hybridoma used was S3H5/ $\gamma 2 \mathrm{bA} 2$, provided by Dr. Mark Kaminski from University of Michigan Medical Center. The antibody produced by this cell line is $\gamma 2 \mathrm{bA}$ anti-idiotype antibody, directed against the $38 \mathrm{C} 13$ (Kaminski et al., 1987).

The cells were grown in RPMI 1640 (Sigma, St.Louis, MO) supplemented with $10 \%$ fetal bovine serum (Gibco Laboratories, Grand Island, NY) and 100 units $/ \mathrm{ml}$ of penicillin and 100 $\mu \mathrm{g} / \mathrm{ml}$ of streptomycin (Sigma). 
The cells were maintained in $T 25 \mathrm{~cm}^{2}$ plastic cell cuture flasks (Bellco Glass, Inc., Vineland, $\mathrm{NJ}$ ) at $37^{\circ} \mathrm{C}$ in a $\mathrm{CO}_{2}$ incubator.

\section{Effect of anchorage dependency on cell growth and MAB production}

Two sets of experiments were performed. All the experiments were conducted in $\mathrm{T} 25 \mathrm{~cm}^{2}$ flasks with and without Sigmacote (Sigma) treatment. For the first experiment, $10^{5}$ cells $/ \mathrm{ml}$ which were exponentially growing were inoculated into $7 \mathrm{~T}$ flasks with and without Sigmacote treatment, respectively. The total working volume was $10 \mathrm{ml}$. One flask was taken daily to count both cells in suspension and cells attached to $\mathrm{T}$ flasks.

For the second experiment, $10^{5}$ cells $/ \mathrm{ml}$ were inoculated into $7 \mathrm{~T}$ flasks. After 3 day cultivation, the number of cells attached at $\mathrm{T}$ flasks was determined from $3 \mathrm{~T}$ flasks. Culture supernatant was completely removed from the remaining $4 \mathrm{~T}$ flasks and saved for collecting spent media and recovering cells in suspension. $5 \mathrm{ml}$ of conditioned media which composed of $2 \mathrm{ml}$ of spent media and $3 \mathrm{ml}$ of fresh media was added to the $4 \mathrm{~T}$ flasks. Cells in suspension of culture supernatant were counted and spun down by centrifugation. Cell concentrations were readjusted with conditioned media in order that the total cell number in $5 \mathrm{ml}$ of conditioned media was the same as the average number of cells that remained attached to each $\mathrm{T}$ flask. Then, $5 \mathrm{ml}$ of cell suspension in conditioned media was added to 4 new $\mathrm{T}$ flask with Sigmacote treatment.

\section{Siliconization $\mathbf{T}$ flasks}

After sterilizing Sigmacote using $0.22 \mu \mathrm{m}$ filter, $4 \mathrm{ml}$ of Sigmacote was added to $\mathrm{T}$ flasks and was used to wet the surfaces.

Excess Sigmacote was drained from $T$ flasks which were then allowed to dry in a laminar flow chamber. Before use, flasks were completely washed two times with sterile distilled water and media, respectively.

\section{Effect of serum concentration on cell anchorage}

T flasks, containing $10 \mathrm{ml}$ of $0,2.5,5,10$ and $20 \mathrm{v} / \mathrm{v} \%$ initial serum concentration, were inoculated with $10^{5}$ cells $/ \mathrm{ml}$.

\section{Analytical methods}

One flask was taken each time and viable cells in suspension were counted by trypan blue exclusion method. The remaining culture supernatant was centrifuged and the the supernatant was aliquoted and kept frozen until the measurement of glucose and antibody. To count the cells attached to $T$ flasks, cells were trypsinized using the trypsin-EDTA (Sigma) after completely removing cell culture supernatant from $\mathbf{T}$ flasks. Cell detachment was watched under the microscope and viable cells were counted using trypan blue exclusion method. The glucose concentration was measured enzymatically using Sigma diagnostic kits (No.315).

$\gamma 2 \mathrm{bA}$ was quantitated using an enzyme linked immunosorbent assay (ELISA). Anti-mouse IgG (Sigma) was used to coat wells of plates at a concentration of $10 \mu \mathrm{g} / \mathrm{ml}$ of PBS overnight at $4^{\circ} \mathrm{C}$. After thes $\epsilon$ plates were washed 4 times, aliquots of culture supernatant and purified MAB $(\mathrm{S} 3 \mathrm{H} 5 / \gamma 2 \mathrm{bA})$ as standards were added to the wells and serially diluted in $1 \%$ bovine serum albumin in PBS. After $45 \mathrm{~min}$ incubation at room temperature, plates were washed and alkaline phosphotase-labelled affinity purified goat antibody against mouse IgG2b (Southern Biotechnology Associates,Inc., Birmingham, AL) was added to plates. After $45 \mathrm{~min}$, the plates were washed 

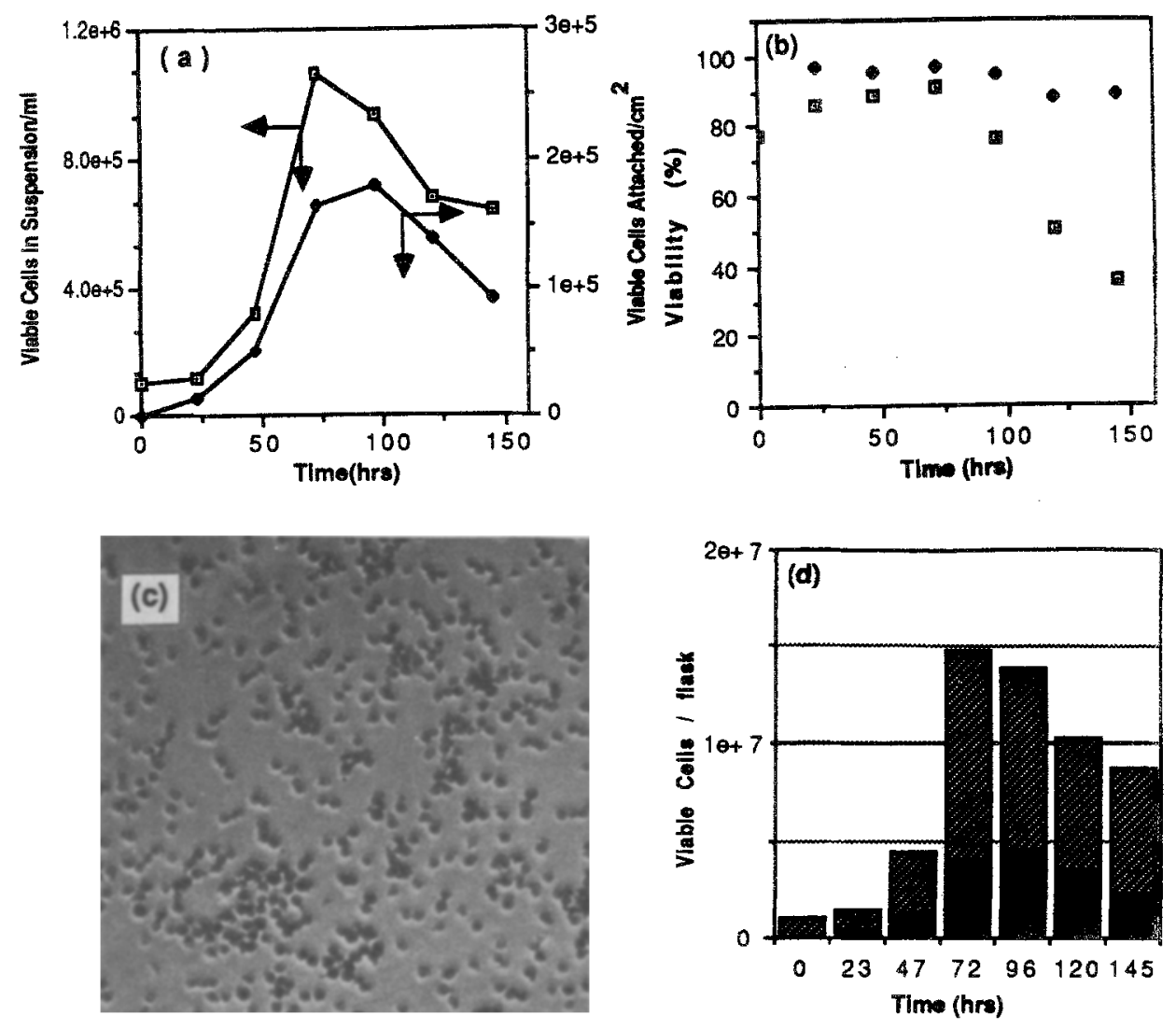

Figure 1: Characteristics of cells grown in T flasks : (a) growth curves (b) viability; - cells attached, - cells in suspension (c) microphotograph of cells attached (d) total viable cells; cells attached, cells in suspension.

and alkaline phosphotase substrate was added. The optical density at $410 \mathrm{~nm}$ of each well was recorded by ELISA reader (Molecular Devices, Palo Alto, CA).

\section{RESULTS AND DISCUSSION}

The typical growth curve of $\mathrm{S} 3 \mathrm{H} 5 / \gamma 2 \mathrm{bA}$ cells is shown in Fig.1(a). Both cells in suspension and cells attached to the flask exhibited exponential growth followed by a decline in viable cell concentration. Cells attached too tightly to the $\mathrm{T}$ flasks to be detached by simple pipetting.

The attached cells maintained about $90 \%$ viable, even at the end of the cultivation, while cells in suspension were only $36 \%$ viable (Fig.1(b)). These results suggest that most of the attached cells are viable and come off when they loose viabilty. Although the attached cells were not confluent as shown Fig.1(c), the maximum concentration of the attached cells was $1.8 \cdot 10^{5} / \mathrm{cm}^{2}$ which was comparable with that reported for HeLa cells $\left(2 \cdot 10^{5} / \mathrm{cm}^{2}\right)$ (Freshney, 1987). As shown in Fig.1(d), the attached cells were about $32 \%$ of the total cells in the $\mathrm{T}$ flask with $10 \mathrm{ml}$ medium. However, this percentage could be increased to more than $55 \%$ in $\mathrm{T}$ flask with $5 \mathrm{ml}$ medium. That is, these cells can be cultivated either in suspension or attached by controlling the ratio of 

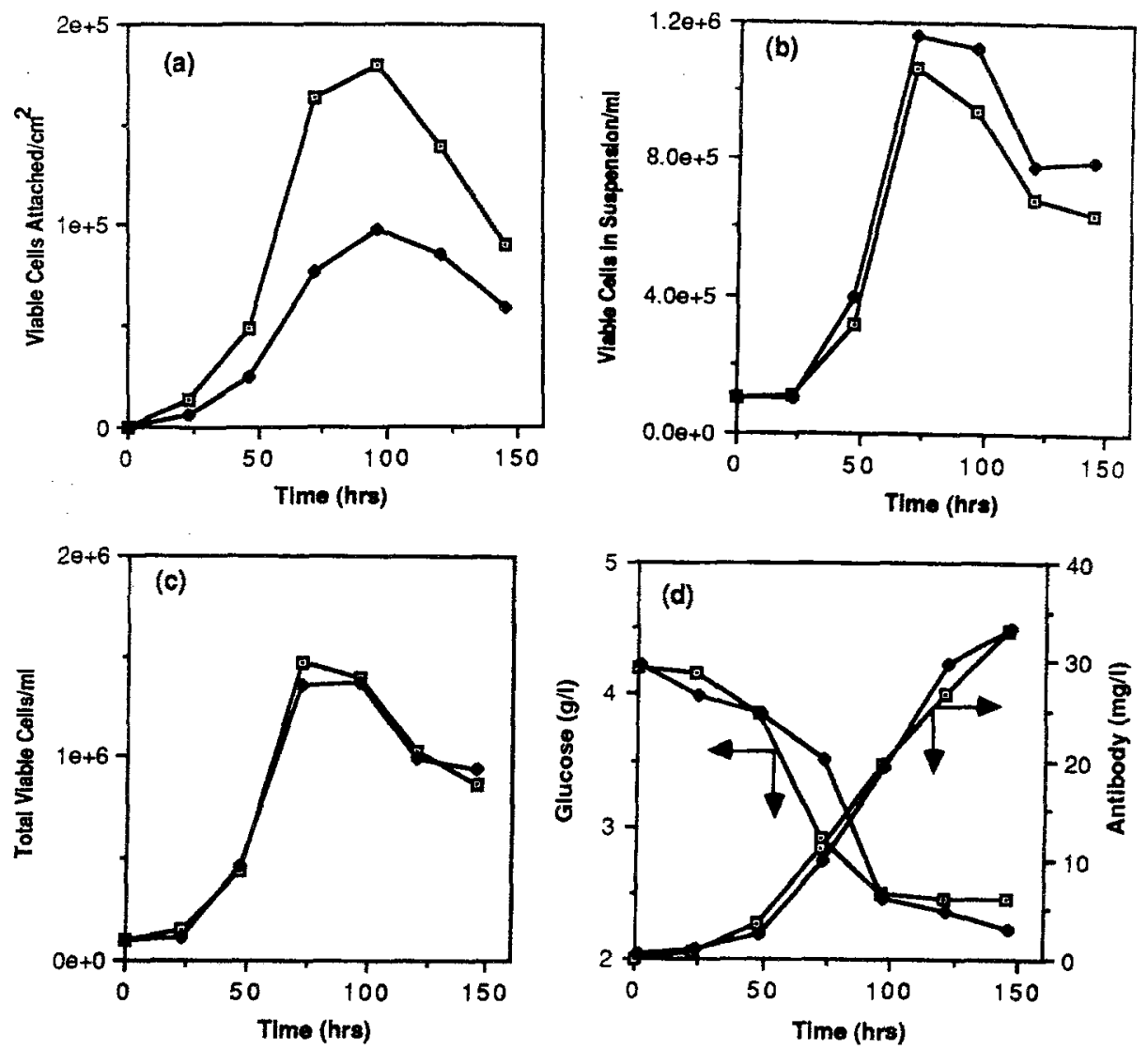

Figure 2: Characteristics of cells grown in $\mathrm{T}$ flasks with and without Sigmacote treatment : 0 cells grown in $\mathrm{T}$ flasks without Sigmacote treatment, $\bullet$ cells grown in T flasks with Sigmacote treatment.

media volume to flask surface area.

To investigate the effect of anchorage-dependency on cell growth and MAB production, cells were inoculated to $\mathrm{T}$ flasks with and without Sigmacote treatment. Sigmacote is a special silicone solution in heptane that easily forms a tight, microscopically thin film on glass. $T$ flasks were siliconized using Sigmacote to prevent cells from attaching to $\mathbf{T}$ flasks. Even though cell attachment could not been prevented completely, the concentration of cells attached to $T$ flask with Sigmacote treatment $\left(0.98 \cdot 10^{5}\right.$ cells $\left./ \mathrm{cm}^{2}\right)$ was significantly lower than that without Sigmacote treatment. However, the number of cells in suspension in $\mathrm{T}$ flasks with Sigmacote treatment was higher than that in $\mathrm{T}$ flasks without Sigmacote treatment. The cell growth curves were almost indentical in both T flasks (Fig.2(b) and (c)). As shown in Fig.2(d), there were no significant differences in MAB production and glucose consumption in both types of cultures. However, it might be difficult to conclude that there was no effect of anchorage dependency on cell growth and MAB production because the difference of the number of cells attached between $\mathrm{T}$ flasks with and without Sigmacote treatment was only $15 \%$ of total cell number in $\mathrm{T}$ flasks. 

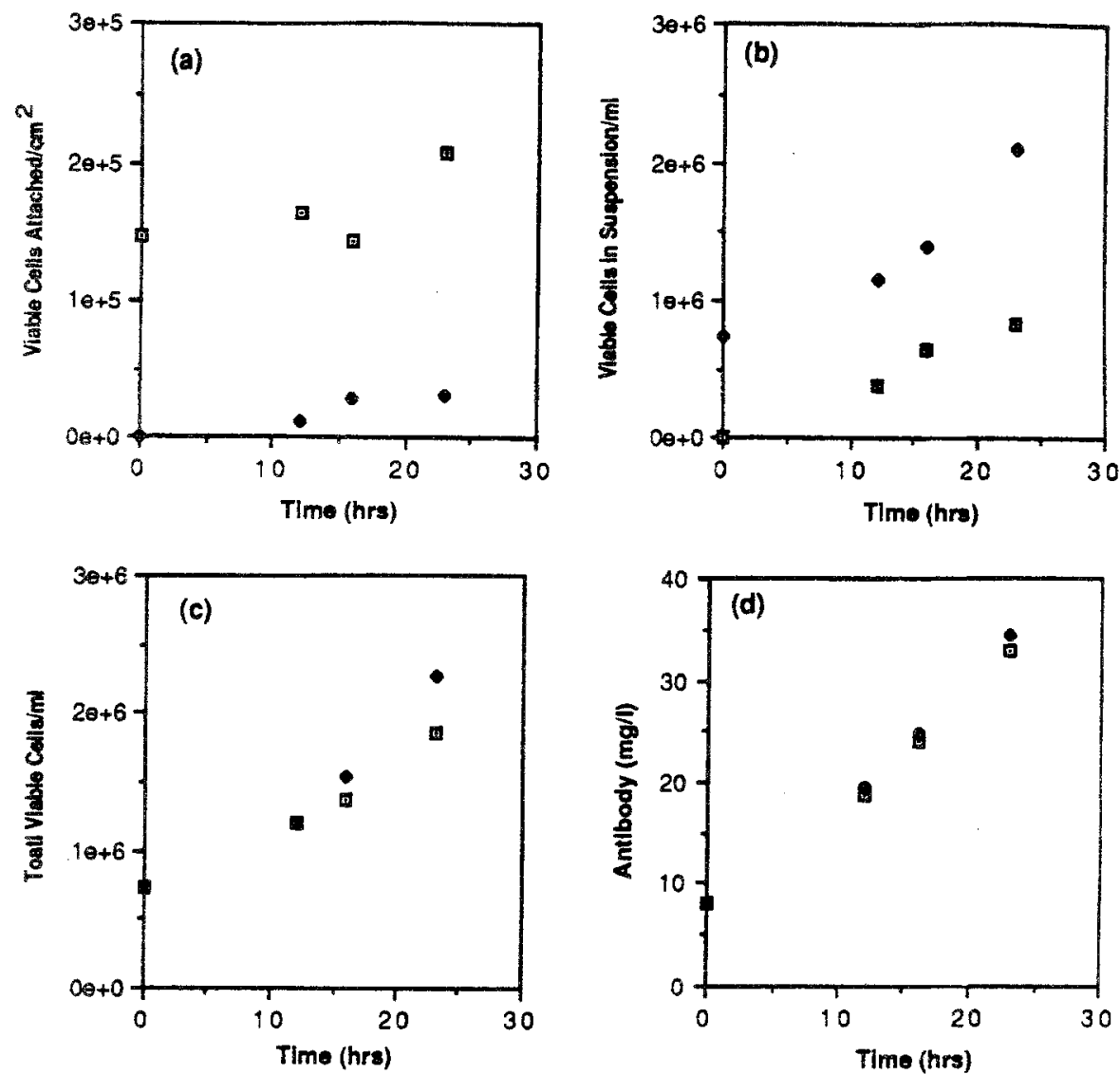

Figure 3: Effect of anchorage dependency on cell growth and MAB production : culture initially with only cells attached, culture initially with only cells in suspension.

Therefore, to study the effect of anchorage dependency more precisely, another set of experiments was carried out with $\mathrm{T}$ flasks initially containing only attached cells and siliconized $\mathrm{T}$ flasks initially containing only cells in suspension. Attached cells were in an exponential growth phase and cell density was $3.66 \cdot 10^{6}$ (standard deviation $=0.81 \cdot 10^{6}$ ) $/$ flask. The same number of suspended cells were inoculated into siliconized $T$ flasks to maximally reduce the number of cells attached. Conditioned media was used to avoid the possible lag phase caused by abrupt change of culture environments. As shown in Fig.3, the attached cells showed almost the same characteristics as cells in suspension with respect to MAB production and cell growth.

Similar results were obtained in the following experiments. The suspended cells were inocilated into the $\mathrm{T}$ flasks at a density of $1 \cdot 10^{5} \mathrm{cells} / \mathrm{ml}$, while the attached cells were recovered by trypsinization and were inoculated into separate $T$ flasks at the same cell density. Cell growth rate and MAB production were almost identical in these two cases (data not shown).

Since serum contains an attachment glycoprotein which is one of the essential factors for adhesion of cells to culture surface, the effect of serum concentration on cell anchorage was investigated (Grinell, 1978). In the absence of protein and divalent cations, cells attach to a culture 

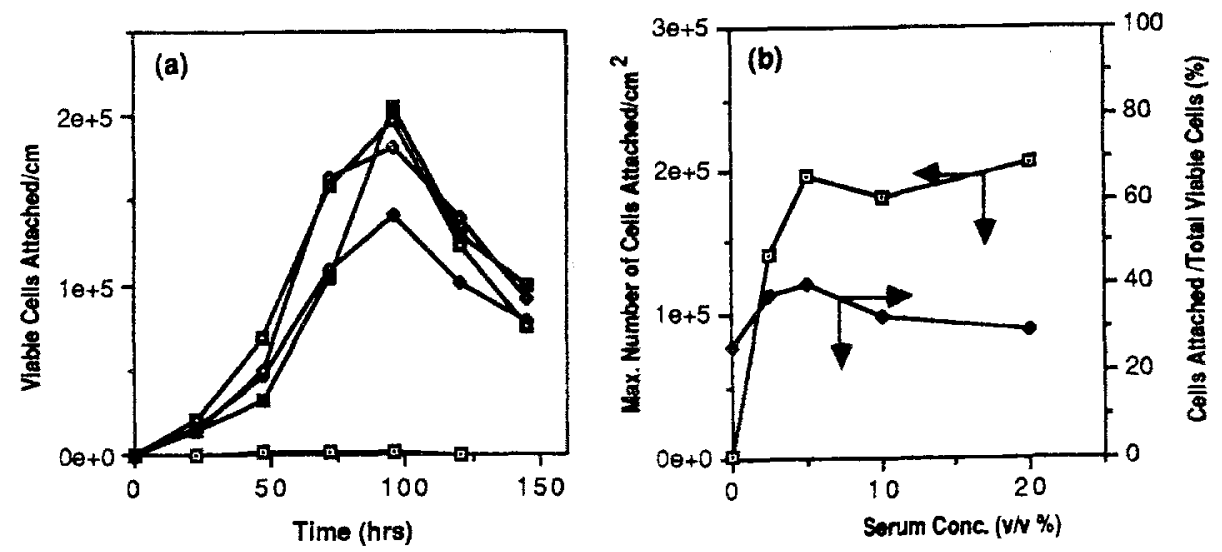

Figure 4: Effect of serum concentration on cell anchorage : - $0 \%,--2.5 \%,--5 \%,--10 \%$, and - - $20 \%$

surface only by non-specific adsorption (Grinell et al ., 1977). As shown in Fig.4, the maximum cell concentration increased with serum concentration up to $5 \%$. At more than $5 \%$ serum concentration, cell concentration was almost constant to $2 \cdot 10^{5} / \mathrm{cm}^{2}$ which would be the maximum concentration obtained. About $30 \%$ of the total viable cells were attached to the surface of $\mathrm{T}$ flasks containing $10 \mathrm{ml}$ of media.

In conclusion, $\mathrm{S3H} 5 / \gamma 2 \mathrm{bA} 2$ hybridoma cells have the same charateristics irrespective of anchorage with respect to cell growth and MAB production.

\section{REFERENCES}

Freshney, R. I. (1987) Culture of animal cells: A manual of basic techniques, N.Y.: Alan R.Liss, Inc., pp64.

Grinnell, F. (1978) Int.Rev.Cytol. 53, 65-144.

Grinell, F., Hays, D. G. and Minter, D. (1977) Exp.Cell Res. 110, 175-190.

Kaminski, M. S., Kitamura, K., Maloney, D. G. and Levy, R. (1987) J.Imumunol. 138, 1298-1296.

Kitano, K., Shintani, Y., Ichimori, Y., Tsukamoto, K., Sasai, S. and Kida, M. (1986) Appl.Micro -biol. Biotechnol. 24, 282-286.

Köhler, G. and Milstein, C. (1975) Nature 256, 495-497.

\section{ACKNOWLEDGEMENT}

The authors thank Dr. Mark Kaminski and Ms. Christina Liu for useful discussions and technical assistance. 